\title{
Impact of Transformational Leadership Behaviors and Psychological Optimism on Subordinate Performance in Taiwan's Tourism Hotel Industry
}

\author{
Tso-Jen Chen ${ }^{1}$, Chi-Min Wu' ${ }^{2}$, Yi-Chou Wang ${ }^{3}$ \\ ${ }^{1}$ Department of Business Administration, Tainan University of Technology, Tainan, Taiwan \\ ${ }^{2}$ Department of Recreation and Health-Care Management, Chia Nan University of Pharmacy \& Science, Tainan, \\ Taiwan \\ ${ }^{3}$ Department of International Business Management, Tainan University of Technology, Tainan, Taiwan \\ Email: ${ }^{*}$ wuchimin@mail.cnu.edu.tw
}

Received 17 June 2015; accepted 7 July 2015; published 14 July 2015

\begin{abstract}
This study proposed a theoretical framework to explore the possible relationship among transformational leadership behavior, psychological optimism, and subordinate performance. Data were surveyed from 169 supervisor-subordinate dyads in Taiwan's tourism hotel industry; we found that transformational leadership behaviors might help individuals nurture higher level of psychological optimism, thus enhancing the subordinate performance. Implication and suggestions were discussed.
\end{abstract}

Keywords

Transformational Leadership Behavior, Psychological Optimism, Subordinate Performance

\section{Introduction}

Leadership scholars have noted that organizational leaders can motivate individuals to exhibit higher level of work effectiveness, such as job satisfaction, task performance, intention to leave, and organizational citizenship behaviors (Colbert, Kristof-Brown, Bradley and Barrick, 2008; Shin, Chiang and Chen, 2012; Wu and Chen, 2015) [1]-[3]. Transformational leadership theory argues that successful leader behaviors may influence, change, and transform employee minds, attitudes and behaviors (Bass, 1985; Brauna, Peusb, Weisweilera and Freya, 2013; Colbert, Kristof-Brown, Bradley and Barrick, 2008; Shin, Chiang and Chen, 2012) [1] [2] [4] [5].

On the other hand, Psychological optimism has been defined as "an individual's positive psychological expectation regarding succeeding now and in the future" (Luthans, Avey, Avolio, Norman and Combs, 2006; Walumbwa, Luthans, Avey and Oke, 2009) [6] [7]. Research on psychological capital has argued that psychological

${ }^{*}$ Corresponding author.

How to cite this paper: Chen, T.-J., Wu, C.-M. and Wang, Y.-C. (2015) Impact of Transformational Leadership Behaviors and Psychological Optimism on Subordinate Performance in Taiwan's Tourism Hotel Industry. Open Journal of Social Sciences, 3, 174-179. http://dx.doi.org/10.4236/jss.2015.37028 
optimism will lead to beneficial attitudinal and behavioral outcomes. While previous research has noted the importance of psychological optimism (Luthans et al., 2006; Walumbwa et al., 2009) [6] [7], the present study tries to understand whether transformational leaders can help individuals develop a higher psychological optimism, thus leading to the beneficial subordinate performance. Besides, this study also pays our attention to understanding the Taiwan hotel industry's difficulty regarding how to improve the subordinate effectiveness in the tourism hotel context, and tries to propose our theoretical model to concern and response above issues. We find that leadership behaviors of tourism hotel organizations can improve their subordinate performance. While improving subordinate performance has become the critical issue for hospitality businesses, the present study may make contributions regarding how tourism organizations leaders can help their subordinates nurture positive psychological optimism, thus leading to better subordinate performance.

\section{Literature Review}

\subsection{Transformational Leadership Behaviors (TFL) and Psychological Optimism}

Strategic leadership theory argued that the role of all organizational leaders is to define strategic goals for their organizations and motivate organization members to engage in their efforts toward these goals (Colbert et al., 2008) [1]. Scholars has pointed that the concepts of transformational leadership behaviors integrate with strategic leadership perspectives and it can help researchers understand the process on how leaders may communicate with organization members and align their efforts to implement organizational strategies (Brauna et al., 2013; Colbert et al., 2008) [1] [5]. Extending from strategic leadership perspective, transformational leadership theory argued that the leader behaviors can effectively influence followers' attitudes and behaviors and induce them to perform beyond exception (Shin et al., 2012; Vera and Crossan, 2004;Brauna et al., 2013) [2] [5] [8]. The core perspectives for TFL theory is that followers' mental model, attitudes, and behaviors can be transformed by the leader's behaviors (Podsakoff, MacKenzie, Moorman and Fetter, 1990) [9]. In this study, we argue that transformational leadership behaviors (TFL) would nurture higher level of psychological optimism. Transformational leadership theory argued that transformational leaders may adopt the ways of inspirational motivation to motivate subordinates to pursue the attractive future and guild them to see the bright side of future success (Colbert et al., 2008; Shin et al., 2012) [1] [2], which would facilitate members' moods and attitudes toward higher degree of optimism. Hence, following above argument, we propose:

Hypothesis 1: Transformational leadership behaviors may be positively related to psychological optimism.

\subsection{Psychological Optimism and Subordinate Performance}

Optimism can be described as "an individual's belief regarding positive expectation now and in the future" (Dangi and Shyam, 2015; Scheier and Carver, 1985; Tyrer, 2014) [10]-[12]. The concept of optimism noted that some individuals tend to be favorable in their judgment regarding what they face in the world. Thus, individuals with higher level of optimism tend to believe that good rather than bad things will happen to them (Black and Reynolds, 2013; Avey, Luthans, and Youssef, 2010) [13] [14]. In contrast, individuals with lower degree of optimism tend to anticipate bad outcome now and in the future (Scheier and Carver, 1985; Dangi et al., 2015) [10] [11]. Youssef et al. (2007) [15] have found that individuals whose expectations are favorable tend to renew their efforts whereas individuals whose expectations are unfavorable tend to reduce their efforts. Positive psychology literature also found that psychological optimism would be positively associated with positive emotion, happiness, satisfaction, and performance (Youssef \& Luthans 2007; Tyrer 2014) [12] [15]. For example, individuals with optimistic beliefs tend to exhibit higher degree of expectations to their futures, generate more active and adaptive coping skills to face their work-related problems, and are less likely to exhibit avoidant ways to treat problems, which would be beneficial to lead to better performance (Avey, Luthans and Youssef, 2010) [14]. Positive psychology literature has noted that the positivity of the individual would contribute to higher performance (West, Patera and Carsten, 2009) [16]. Individuals high in psychological optimism tend to generate effective paths and ways to pursue their objectives, exhibit higher expectation to the future, exhibit more confidences to accomplish their tasks which would motivate them engage in more efforts and resources to achieve their tasks and thus lead to greater task performance (Black et al., 2013; Dangi et al., 2015; Luthans, Norman, Avolio and Avey, 2008) [10] [13] [17]. Thus, in this study, we predict that psychological optimism will lead to higher subordinate performance.

Hypothesis 2: Psychological optimism may be positively related to subordinate performance. 


\subsection{The Mediated Effect of Psychological Optimism on Subordinate Performance}

As discussed above (Hypothesis 1 and hypothesis 2), we link the hypothesis 1 and hypothesis 2, and further argue that transformational leadership behaviors would be able to lead to better subordinate performance when they can help subordinates develop higher degree of psychological optimism. In other words, transformational leadership behaviors affect subordinate performance through their effects on psychological optimism. Thus, we predict that psychological optimism will play the mediating role in the relationship between transformational leadership behaviors and subordinate performance. Following above argument, we propose:

Hypothesis 3: Psychological optimism will mediate the relationship between transformational leadership behaviors and subordinate performance.

\section{Methods}

\subsection{Sample and Collection}

This study use a questionnaire-based methodology to collect data in the tourism hotels listed as members of the Taiwan's hotel industry. The resultant list yields a target sample 169 supervisor-subordinate dyads of tourism hotels in Taiwan. Subordinate of tourism hotels rated the scales of transformational leadership behaviors and psychological optimism while supervisor rated the subordinate performance. Tourism hotel subordinates were largely female (60.9\%); $85.6 \%$ were less than 30 years old; and $56.2 \%$ had completed university education while tourism hotel supervisor were mainly male (58.7\%), $63.4 \%$ were over 39 years, and $75.3 \%$ had the university education degree.

\subsection{Measure}

We used the Multifactor Questionnaire (MLQ Form 5 X.; Bass and Avolio, 1995; 2000) [18] [19] to assess the four dimensions of transformational leadership, including idealized influence, inspirational motivation, intellectual stimulation, and individual consideration. Examples of items includes: "Talks optimistically about the future"; "Articulates a compelling vision of the future"; "Expresses confidence that goals will be achieved"; "Seeks differing perspectives when solving problems"; "Gets me to look at problems from many different angles"; "Suggests new ways of looking at how to complete assignments". On the other hand, we used the psychological capital questionnaire (Luthans, Avolio, Avey and Norman, 2007) [20] to assess psychological optimism. Examples of items includes: "In uncertain times, I usually expect the best"; "I always look on the bright side of things"; "I am always optimistic about my future"; "I am believer in the idea that "every cloud has a silver lining". Finally, we assessed task performance developed from Tsui, Pearce, Porter and Tripoli (1997) [21]. Example of items include "The subordinate's quality of work is much higher than average"; "The subordinate's efficiency is much higher than average"; "The subordinate's standards of work quality are bigger than the formal standards for this job"; "The subordinate strives for bigger quality work than required". The reliability and construct validity of above scales shown acceptance levels in this study.

\section{Results}

\subsection{Descriptive Analysis}

Table 1 shows mean values, standard deviations, and zero-order correlations among the constructs. The average values of all research constructs are between 3.39 and 3.46, with standard deviations between 0.83 and 1.05. Additionally, as expected, Pearson correlation analysis result shows that all factors are interrelated. Transformational leadership behaviors (TFL) were positively to psychological optimism $(\gamma=0.49, \mathrm{p}<0.001)$ and subordinate performance $(\gamma=0.34, \mathrm{p}<0.01)$. Meanwhile, psychological optimism was positively related to subordinate performance $(\gamma=0.32, \mathrm{p}<0.01)$.

\subsection{Hypotheses Test}

We used structural model analysis to examine our hypotheses. Structural model analysis result showed that the proposed model demonstrated a reasonable fit $\left(\chi^{2}=230.756, \mathrm{p}=0.000\right), \chi^{2} / \mathrm{df}=1.98, \mathrm{CFI}=0.951$, TLI $=0.94$, and RMR $=0.058$ ). Firstly, for direct effects, we used standardized path coefficients to determine whether Hy- 
potheses 1 and Hypotheses 2 were supported. As depicted in Figure 1, we found a strong, positive relationship between transformational leadership behaviors and psychological optimism, thus supporting Hypotheses $1(\gamma=$ $0.54, \mathrm{p}<0.001)$. Besides, the coefficient of the path from psychological optimism to subordinate performance was significant, thus supporting Hypothesis $2(\gamma=.34, \mathrm{p}<0.001)$. Secondly, to test the mediating relationships among transformational leadership behaviors, psychological optimism, and subordinate performance, we conducted three structural models and used Baron and Kenney's (1986) [22] analytic procedures to examine the mediated effects of psychological optimism in this study. The three structural models include a) Model 1 (direct effects) with only paths from TFL to subordinate performance; b) Model 2 (full mediation) with paths only from TFL to psychological optimism and paths from psychological optimism to subordinate performance; c) Model 3 (partially mediation) with identical paths of model 2 and additional TFL to subordinate performance. A full mediating relationship will be confirmed if the resulting path coefficients of model 1 and model 2 are significant and the direct paths from TFL to subordinate performance are not significant. However, the partially mediation will be predicted if the resulting path coefficients of model 1 and model 2 are significant and the direct paths from independent variables to dependent variables is significant. Following above analytical procedures, we tested our hypothesis 3. Table 2 shows the model fit statistics, and Table 3 presents the path coefficients of the three models. As showed in Table 3, for model 1, the resulting path coefficients were significant from TFL to subordinate performance $(\gamma=0.47, \mathrm{p}<0.001)$. In addition, for model 2 , the resulting path coefficients were significant from TFL to psychological optimism $(\gamma=0.54, \mathrm{p}<0.001)$, and from psychological optimism to subordinate performance $(\gamma=0.48, \mathrm{p}<0.001)$. Finally, for model 3 , the significant path coefficient paths were found from TFL to psychological optimism $(\gamma=0.54, \mathrm{p}<0.001)$, and from psychological optimism to subordinate performance $(\gamma=0.34, \mathrm{p}<0.001)$, but the direct paths from TFL to subordinate performance were also significant $(\gamma=$ $0.29, \mathrm{p}<0.001)$. Based on above results, we predicted that psychological optimism mediated the relationship between transformational leadership behaviors and subordinate performance. Hypotheses 3 were supported in-

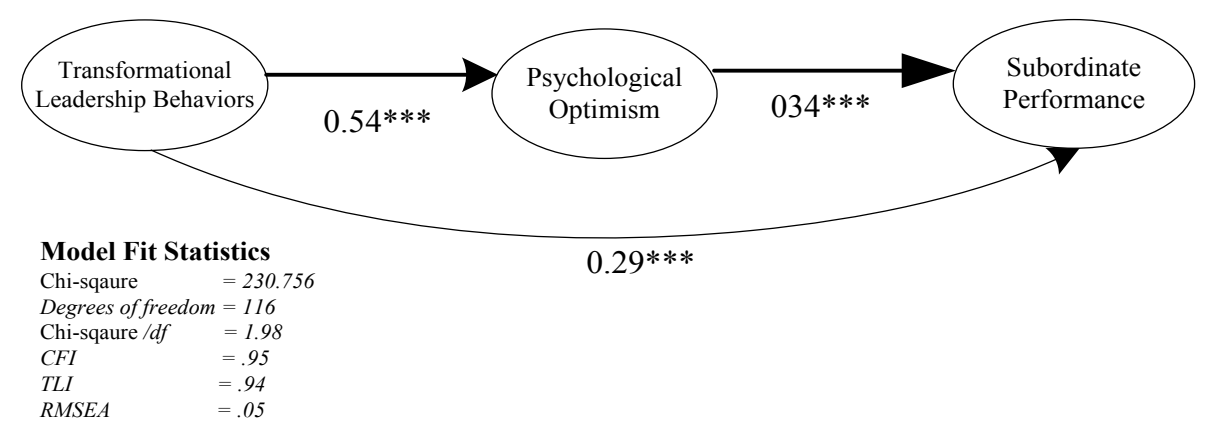
a Path coefficients are standardized, maximum-likelihood. The indirect effect of transformational leadership behaviors on
subordinate performance has a coefficient of 0.18 . $* * * \mathrm{P}<.001$

Figure 1. Results for structural model analysis.

Table 1. Means, standard deviations, and correlations.

\begin{tabular}{|c|c|c|c|c|c|c|c|c|}
\hline & Mean & s.d & 1 & 2 & 3 & 4 & 5 & 6 \\
\hline 1. sex & 0.39 & 0.50 & & & & & & \\
\hline 2. age & 1.89 & 0.69 & -0.035 & & & & & \\
\hline 3. education & 2.75 & 0.54 & 0.009 & -0.051 & & & & \\
\hline $\begin{array}{l}\text { 4. transformational leadership } \\
\text { behavior }\end{array}$ & 3.39 & 0.99 & 0.145 & -0.071 & 0.011 & $(0.94)$ & & \\
\hline 5. psychological optimism & 3.44 & 1.05 & -0.011 & -0.032 & -0.061 & $0.49^{* *}$ & $(0.92)$ & \\
\hline 6. subordinate performance & 3.46 & 0.83 & 0.069 & 0.082 & -0.044 & $0.34^{* *}$ & $0.32^{* *}$ & $(0.89)$ \\
\hline
\end{tabular}

${ }^{a} \mathrm{~N}=169$, alpha reliabilities are given in parentheses. 'Sex was dummy-coded as 1, "male" and 0, "female". Age had four categories: under 25,26 - 30, 31 40 , and over 40. Education had four categories: middle school and under middle school, high school, university, and graduate school. ${ }^{* *} \mathrm{p}<0.01$. 
Table 2. Fit results for structural equation model.

\begin{tabular}{cccccc}
\hline & & & Fit & \\
\hline & $\chi^{2}$ & df & CFI & TLI & RMR \\
\hline Model 1 & $126.96^{* * *}$ & 43 & 0.94 & 0.92 & 0.04 \\
Model 2 & $245.64^{* * *}$ & 117 & 0.94 & 0.93 & 0.09 \\
Model 3 & $230.756^{* * *}$ & 116 & 0.95 & 0.94 & 0.05 \\
\hline
\end{tabular}

Table 3. Structural equation path coefficients.

\begin{tabular}{|c|c|c|c|}
\hline & \multicolumn{3}{|c|}{ Completely standardized path coefficients } \\
\hline & Model 1 & Model 2 & Model 3 \\
\hline $\mathrm{TFL} \rightarrow$ task performance & $0.47\left(^{* * *}\right)$ & & $0.29\left(^{* * *}\right)$ \\
\hline $\mathrm{TFL} \rightarrow$ psychological optimism & & $0.54\left(^{* * *}\right)$ & $0.54\left({ }^{* * *}\right)$ \\
\hline psychological optimism $\rightarrow$ subordinate performance & & $0.48\left(^{* * *}\right)$ & $0.34\left(^{* * *}\right)$ \\
\hline
\end{tabular}

this study (partially mediation).

\section{Conclusion}

The testing of Hypothesis 1 notes that transformational leadership behaviors are positively related to psychological optimism while the results of Hypothesis 2 also find that psychological optimism is positively related to subordinate performance. Finally, the results of Hypothesis 3 suggest that psychological optimism will mediate the relationship between transformational leadership behaviors (TFL) and subordinate performance. The primary goal of this study is to examine the mediation mechanism between transformational leadership behaviors and subordinate performance. We aim to extend the literature in two ways. Firstly, our study notes that transformational leadership behaviors will enhance subordinate performance indirectly, through its increase in psychological optimism. In this respect, our research contributes to exploring mediation mechanism that underlies the influence of transformational leader on subordinate performance and helping explicate the process through which transformational leadership behaviors influence employee outcomes (Bass, 1999; Yukl, 1999) [23] [24]. Secondly, previous research notes that psychological optimism may lead to beneficial outcomes, but the possible antecedent is still unclear. Based on transformational leadership theory, we note that transformational leadership behaviors will develop higher psychological optimism, which will contribute to literature of psychological optimism. Finally, we collect data from Taiwan tourism hotel industry and explore tourism organization leaders' behavior and their subordinate, which supplement the knowledge of lack of how to improve subordinate performance in Taiwan tourism hotel organizations. For practical implication, with regard to the importance of psychological optimism acting a mediating role in the relationship between transformational leadership behaviors and subordinate performance in the hotel context, this study notes that tourism hotel's supervisors have to promote subordinates' understanding on hotel's objectives and vision and further influence subordinates' optimism to face the future challenge. In addition, positive workplace attitude and climate also have to be established by hotel transformational supervisors to lead an optimistic psychological state for enhancing subordinates performance.

\section{References}

[1] Colbert, A.E., Kristof-Brown, A.L., Bradley, B.H. and Barrick, M.R. (2008) CEO Transformational Leadership: The Role of Goal Importance Congruence in Top Management Team. Academy of Management Journal, 51, 81-96. http://dx.doi.org/10.5465/AMJ.2008.30717744

[2] Shin, H.A., Chiang, Y.H. and Chen, T.J. (2012) Transformational Leadership, Trusting Climate, and Knowledge-Exchange Behavior in Taiwan. The International Journal of Human Resource Management, 23, 1057-1073. http://dx.doi.org/10.1080/09585192.2011.639546 
[3] Wu, C.M. and Chen, T.J. (2015) Psychological Contract Fulfillment in the Hotel Workplace: Empowering Leadership, Knowledge Exchange, and Service Performance. International Journal of Hospitality Management. http://dx.doi.org/10.1016/j.ijhm.2015.04.008

[4] Bass, B.M. (1985) Leadership and Performance beyond Expectations. Free Press, New York.

[5] Brauna, S., Peusb, C., Weisweilera, S. and Freya, D. (2013) Transformational Leadership, Job Satisfaction, and Team Performance: A Multilevel Mediation Model of Trust. Leadership Quarterly, 24, 270-283. http://dx.doi.org/10.1016/j.leaqua.2012.11.006

[6] Luthans, F., Avey, J.B., Avolio, B.J., Norman, S.M. and Combs, G.M. (2006) Psychological Capital Development: Toward a Micro-Intervention. Journal of Organizational Behavior, 27, 387-393. http://dx.doi.org/10.1002/job.373

[7] Walumbwa, F.O., Luthans, F., Avey, J.B. and Oke, A. (2009) Authentically Leading Groups: The Mediating Role of Collective Psychological Capital and Trust. Journal of Organizational Behavior. www.interscience.wiley.com

[8] Vera, D. and Crossan, M. (2004) Strategic Leadership and Organizational Learning. Academy of Management Review, 29, 222-240.

[9] Podsakoff, P.M., MacKenzie, S.B., Moorman, R.H. and Fetter, R. (1990) Transformational Leader Behaviors and Their Effects on Followers' Trust in Leader, Satisfaction, and Organizational Citizenship Behaviors. Leadership Quarterly, 1, 107-142. http://dx.doi.org/10.1016/1048-9843(90)90009-7

[10] Dangi, S. and Shyam, R. (2015) Optimism, Adjustment, and Appraisal among Adolescents. Indian Journal of Positive Psychology, 6, 75-78.

[11] Scheier, M.F. and Carver, C.S. (1985) Optimism, Coping, and Health: Assessment and Implications of Generalized Outcome Expectancies. Health Psychology, 4, 219-247. http://dx.doi.org/10.1037/0278-6133.4.3.219

[12] Tyrer, S. (2014) Resiliency and the Nurse Leader: The Importance of Equanimity, Optimism, and Perseverance. Nursing Management, 45, 46-50.

[13] Black, J. and Reynolds, W.M. (2013) Examining the Relationship of Perfectionism, Depression, and Optimism: Testing for Mediation and Moderation. Personality and Individual Difference, 54, 426-431. http://dx.doi.org/10.1016/j.paid.2012.10.012

[14] Avey, J.B., Luthans, F. and Youssef, C.M. (2010) The Additive Value of Positive Psychological Capital in Predicting Work Attitudes and Behaviors. Journal of Management, 36, 430-452. http://dx.doi.org/10.1177/0149206308329961

[15] Youssef, C.M. and Luthans, F. (2007) Positive Organizational Behavior in the Workplace: The Impact of Hope, Optimism, and Resilience. Journal of Management, 33, 774-800. http://dx.doi.org/10.1177/0149206307305562

[16] West, B.J., Patera, J.L. and Carsten, M.K. (2009) Team Level Positivity: Investigating Positive Psychological Capacities and Team Level Outcomes. Journal of Organizational Behavior, 30, 249-267. http://dx.doi.org/10.1002/job.593

[17] Luthans, F., Norman, S.M., Avolio, B.J. and Avey, J.B. (2008) The Mediating Role of Psychological Capital in the Supportive Organizational Climate-Employee Performance Relationship. Journal of Organizational Behavior, 29, 219 238. http://dx.doi.org/10.1002/job.507

[18] Bass, B.M. and Avolio, B.J. (1995) MLQ: Multifactor Leadership Questionnaire. Mind Garden, Redwood City.

[19] Bass, B.M. and Avolio, B.J. (2000) Manual for the Multifactor Leadership Questionnaire (Form 5X). Mindgarden, Redwood City.

[20] Luthans, F., Avolio, B.J., Avey, J.B. and Norman, S.M. (2007) Positive Psychological Capital: Measurement and Relationship with Performance and Satisfaction. Personnel Psychology, 60, 541-572. http://dx.doi.org/10.1111/j.1744-6570.2007.00083.x

[21] Tsui, A.S., Pearce, J.L., Porter, L.W. and Tripoli, A.M. (1997) Alternative Approaches to the Employee-Organization Relationship: Does Investment in Employees Pay Off? Academy of Management Journal, 40, 1089-1121. http://dx.doi.org/10.2307/256928

[22] Baron, R.M. and Kenny, D.A. (1986) The Moderator-Mediator Variable Distinction in Social Psychological Research: Conceptual, Strategic and Statistical Considerations. Journal of Personality and Social Psychology, 51, 1177-1182. http://dx.doi.org/10.1037/0022-3514.51.6.1173

[23] Bass, B.M. (1999) Two Decades of Research and Development in Transformational Leadership. European Journal of Work and Organizational Psychology, 8, 9-32. http://dx.doi.org/10.1080/135943299398410

[24] Yukl, G. (1999) An Evaluation of Conceptual Weaknesses in Transformational and Charismatic Leadership Theories. Leadership Quarterly, 10, 285-305. http://dx.doi.org/10.1016/S1048-9843(99)00013-2 